\title{
Hypoglossal-Facial Anastomosis for Facial Nerve Reconstruction: Outcomes using the Side-to-End Surgical Technique
}

\section{Anastomose Hipoglosso-Facial para reanimação do nervo facial: Resultados da técnica término-lateral}

Leonardo Gilmone Ruschel ${ }^{4}$ Joel Sanabria Duarte ${ }^{1}$ Jonathan De La Cruz ${ }^{1}$ Kristel Back Merida ${ }^{2}$ Gustavo Fabiano Nogueira ${ }^{3}$ Matheus Fernandes de Oliveira, ${ }^{4,5}$ Ricardo Ramina ${ }^{1}$

${ }^{1}$ Neurosurgery Department, Instituto de Neurologia de Curitiba (INC), Curitiba, Paraná, Brazil

2 Neurology Department, Instituto de Neurologia de Curitiba (INC), Curitiba, Paraná, Brazil

${ }^{3}$ Otorhinolaryngology Department, Instituto de Neurologia de Curitiba (INC), Curitiba, Paraná, Brazil

${ }^{4}$ DFV Neuro Neurology and Neurosurgery Service, São Paulo, Brazil

${ }^{5}$ Neurosurgery Department, Hospital do Servidor Público Estadual de São Paulo, São Paulo, Brazil

Arq Bras Neurocir 2021;40(3):e222-e228.
Address for correspondence Matheus Fernandes de Oliveira, MD, PhD, Av. Loefgren, 700, apto 103, Vila Mariana, São Paulo, São Paulo, 04040-000, Brazil (e-mail: mafernoliv@yahoo.com.br).

\begin{abstract}
Keywords

- facial-nerve trauma

- facial nerve

- hypoglossal nerve

- facial paralysis

- surgical anastomosis
\end{abstract}

Introduction The side-to-end hypoglossal-facial anastomosis (HFA) technique is an excellent alternative technique to the classic end-terminal anastomosis, because it may decrease the symptoms resulting from hypoglossal-nerve transection.

Methods Patients with facial nerve palsy (House-Brackmann [HB] grade VI) requiring facial reconstruction from 2014 to 2017 were retrospectively included in the study.

Results In total, 12 cases were identified, with a mean follow-up of 3 years. The causes of facial paralysis were due to resection of posterior-fossa tumors and trauma. There was improvement in $91.6 \%$ of the patients $(11 / 12)$ after the HFA. The rate of improvement according to the HB grade was as follows: HB III - 58.3\%; HB IV $16.6 \%$; and $\mathrm{HB}$ II $-16.6 \%$. The first signs of improvement were observed in the patients with the shortest time between the paralysis and the anastomosis surgery ( 3.5 months versus 8.5 months; $p=0.011$ ). The patients with $\mathrm{HB}$ II and III had a shorter time between the diagnosis and the anastomosis surgery (mean: 5.22 months), while the patients with HB IV and VI had a longer time of paresis (mean: 9.5 months; $p=0.099$ ). We did not observe lingual atrophy or changes in swallowing.

Discussion and Conclusion Hypoglossal-facial anastomosis with the terminolateral technique has good results and low morbidity in relation to tongue motility and swallowing problems. The HB grade and recovery appear to be better in patients operated on with a shorter paralysis time. received

March 23, 2020

accepted

August 5, 2020

published online

October 16, 2020
DOI https://doi.org/ 10.1055/s-0040-1718431. ISSN 0103-5355.

\footnotetext{
(c) 2020. Sociedade Brasileira de Neurocirurgia. All rights reserved. This is an open access article published by Thieme under the terms of the Creative Commons Attribution-NonDerivative-NonCommercial-License, permitting copying and reproduction so long as the original work is given appropriate credit. Contents may not be used for commercial purposes, or adapted, remixed, transformed or built upon. (https://creativecommons.org/ licenses/by-nc-nd/4.0/) Thieme Revinter Publicações Ltda., Rua do Matoso 170, Rio de Janeiro, RJ, CEP 20270-135, Brazil
} 


\section{Resumo \\ Palavras-chave \\ - trauma do nervo facial \\ - nervo facial \\ - nervo hipoglosso \\ - paralisia facial \\ - anastomose cirúrgica \\ Introdução A técnica de Anastomose Hipoglosso-Facial término-lateral é uma técnica excelente alternativa à clássica Anastomose Término-Terminal, pois pode diminuir os sintomas resultantes da transecção do nervo hipoglosso. \\ Métodos Pacientes com paralisia do nervo facial (grau VI de House-Brackmann) com necessidade de reconstrução facial foram incluídos retrospectivamente de 2014 a 2017. \\ Resultados Doze casos foram identificados com um seguimento médio de 3 anos. As causas da paralisia facial foram devido à ressecção de tumores da fossa posterior e trauma. Houve melhora em $91,6 \%$ dos pacientes (11/12) após a cirurgia. A maioria dos pacientes apresentou melhora com HB III, 58,3\%, grau IV 16,6\%, grau II 16,6\%. Os primeiros sinais de melhora foram nos pacientes com menor tempo entre a cirurgia de paralisia e anastomose ( 3,5 meses vs. 8,5 meses) $(p=0,011)$. Pacientes com HB II e III tiveram menor tempo entre o diagnóstico e a cirurgia da anastomose (média de 5,22 meses), enquanto os pacientes com HB IV e VI tiveram um tempo maior de paresia (média de 9,5 meses) $(p=0,099)$. Não observamos atrofia lingual ou alterações na deglutição. \\ Discussão e Conclusão A Anastomose Hipoglosso-Facial término-lateral apresenta bons resultados e baixa morbidade em relação à motilidade da língua e problemas de deglutição. O grau (HB) e a recuperação parecem ser melhores em pacientes operados com menor tempo de paralisia.}

\section{Introduction}

Despite the remarkable development of microsurgical techniques and advances in intraoperative facial-nerve monitoring, facial paralysis remains a feared drawback and a major challenge for the neurosurgeon. ${ }^{1,2}$ Paralysis of facial-expression muscles is a debilitating and psychologically devastating condition for the patient, leading to a degree of emotional disability related to self-esteem. ${ }^{3}$ To reduce this social impact, several techniques for facial-nerve restoration have been described, including nerve anastomosis, free-muscle transplantation, and lengthening temporalis myoplasty. ${ }^{4,5}$

Despite the development of new microsurgical techniques, facial-nerve rehabilitation remains challenging. It is known that end-to-end primary facial-nerve repair, with or without graft interposition, offers the best hope for recovery in intracranial and extracranial facial-nerve transection., ${ }^{4,5}$ Occasionally, this anastomosis cannot be performed as readily, especially in cases in which the proximal stump of the facial nerve in the brainstem is not available, as well as in cases of facial-nucleus destruction, or even after degenerative nerve alterations. ${ }^{6-8}$ In these cases, hypoglossal-facial neurorrhaphy is one of the best techniques available to restore the dynamic expression of the face, and is probably the most used technique after total facial-nerve rupture in the cerebellopontine angle (CPA). ${ }^{5,6,8-10}$

The favorable outcomes in facial-nerve recovery do not hide the side effects of the end-to-end anastomosis that are associated with the inevitable hypoglossal-nerve atrophy, mass movements of the face and speech, and chewing and swallowing difficulties that interfere with daily life. ${ }^{7,9-11}$ Variations of this technique have been described since 1991, with May's technique using cable graft. ${ }^{12} \mathrm{~A}$ side-to-end hypoglossal-facial neurorrhaphy with translocation of the intratemporal facial nerve to the lateral portion of the hypoglossal nerve was described in 1997 by Darrouzet with similar results, minimizing tongue atrophy and speech disorders. ${ }^{13-15}$ Recently, an hemihypoglossal facial-anastomosis technique has been described with minimal tongue atrophy. ${ }^{16}$

In the present article, we describe our experience and results with a case series of 12 patients with facial paralysis submitted to hypoglossal-facial anastomosis (HFA) by the side-to-end technique, regarding the assessment of the preoperative and postoperative factors and recovery of facial-nerve function.

\section{Methods}

The clinical, surgical and hospital records of the patients who underwent surgery for facial hypoglossal-anastomosis due to secondary facial paralysis were reviewed from 2014 to 2017 at Instituto de Neurologia de Curitiba (INC). All surgeries were performed by a single skull-base neurosurgeon (Ramina R).

Preoperatively and postoperatively, we recorded data from the medical records regarding demographics (age, sex, economic stratum), the examination of the cranial nerves (facial mimic, facial tonicity, tongue atrophy and swallow disorders). The clinical follow-up was performed at 3, 6 and 12 months. The patients lost to follow up were excluded. Other recorded information included etiology of the facial paralysis, the House-Brackmann (HB) facial grading system, and electromyography. A total of 12 patients met these criteria. The time of facial paralysis was counted as the onset of paresis until the day 
of surgery; in addition, if it presented some type of recovery after surgery, it was called recovery time. The study was approved by the Ethics and Research Committee of INC.

\section{Statistical Analysis}

The data was analyzed using the Statistical Package for the Social Sciences (SPSS, IBM Corp., Armonk, NY, US) software, version 21.0. The qualitative variables are described as frequency and percentages; the quantitative variables are presented as mean values. In order to find differences between the quantitative variables, the non-parametric Mann-Whitney $U$ test was used, as the numerical variables were not normally distributed. The statistical significance was set at a $p<0.05$.

\section{Surgical Anatomy and the Technique (Side-to-End HFA)}

The patient is placed in the supine position with the head turned $45^{\circ}$ to the contralateral side. A retroauricular-arch incision is made $2 \mathrm{~cm}$ from the ear, exposing the mastoid, extending it caudally along the anterior border of the sternocleidomastoid muscle (SCM) until just above the angle of the mandible. The greater auricular nerve that runs in the subcutaneous fat tissue is dissected and preserved to avoid transient sensitive disorders of the pinna and mandibular angle. The mastoid tip is exposed by removing the muscle attachments.

The facial nerve must be identified where it leaves the skull in the stylomastoid foramen, anterior to the SCM at the mastoid process (-Fig. 1). The styloid process is an important anatomical reference when locating the main trunk of the facial nerve, which is lateral from this slender bone, leading the surgeon to the stylomastoid foramen, where the nerve can be identified. It is possible to expose and mobilize the nerve trunk with or without mastoidectomy (-Fig. 1).

The hypoglossal nerve is found deep in the posterior belly of the digastric muscle at the caudal end of the incision. It is confirmed with a nerve stimulator, followed and dissected proximally (-Fig. 1).

Partial mastoidectomy of the anterior triangle-shaped part of the mastoid process is performed with a diamond drill, leaving only a thin layer of bone over the facial nerve, which is then removed using a microdissector. The facial nerve is exposed up to its external genu and geniculate ganglion, the stylomastoid foramen is opened, and the nerve is released from the connective tissue and to the parotid gland. The facial nerve is sectioned near its external genu and then displaced caudally toward the previously isolated hypoglossal nerve. The anastomosis point is defined between the proximal portion of the facial nerve and the lateral portion of the hypoglossal nerve. A longitudinal neurotomy is performed, and the facial nerve is attached to the suture. The facial nerve passes beneath the digastric muscle without any tension in order for us to perform a suture with a 10.0 nylon suture. Then, a thin layer of fibrin glue is placed at the anastomosis site. Cautiously, hemostasis is performed, as we do not leave the suction drain at closing (-Fig. 2).

\section{Results}

In total, 12 patients were submitted to this procedure from 2014 to 2017, with an average follow-up of 3 years (-Table 1); 8 patients were men (66.6\%), and 4 were women (33.4\%). Their ages ranged from 7 to 65 years, and the average age was 46 years among men, and 55 years among women. The facial paresis occurred at the left side in 6 subjects (50\%), and at the right side in the other 6 subjects (50\%).

Among the 12 cases, in 9 (75\%) patients the procedure was secondary to surgery for skull-base tumors. Vestibular schwannoma (VS) larger than $3.5 \mathrm{~cm}$ was the cause in 7 cases; 1 case was a patient with a CPA meningioma, and there was another patient with jugular glomus tumor. The three remaing patients had brainstem cavernoma, facial trauma and congenital paralysis.
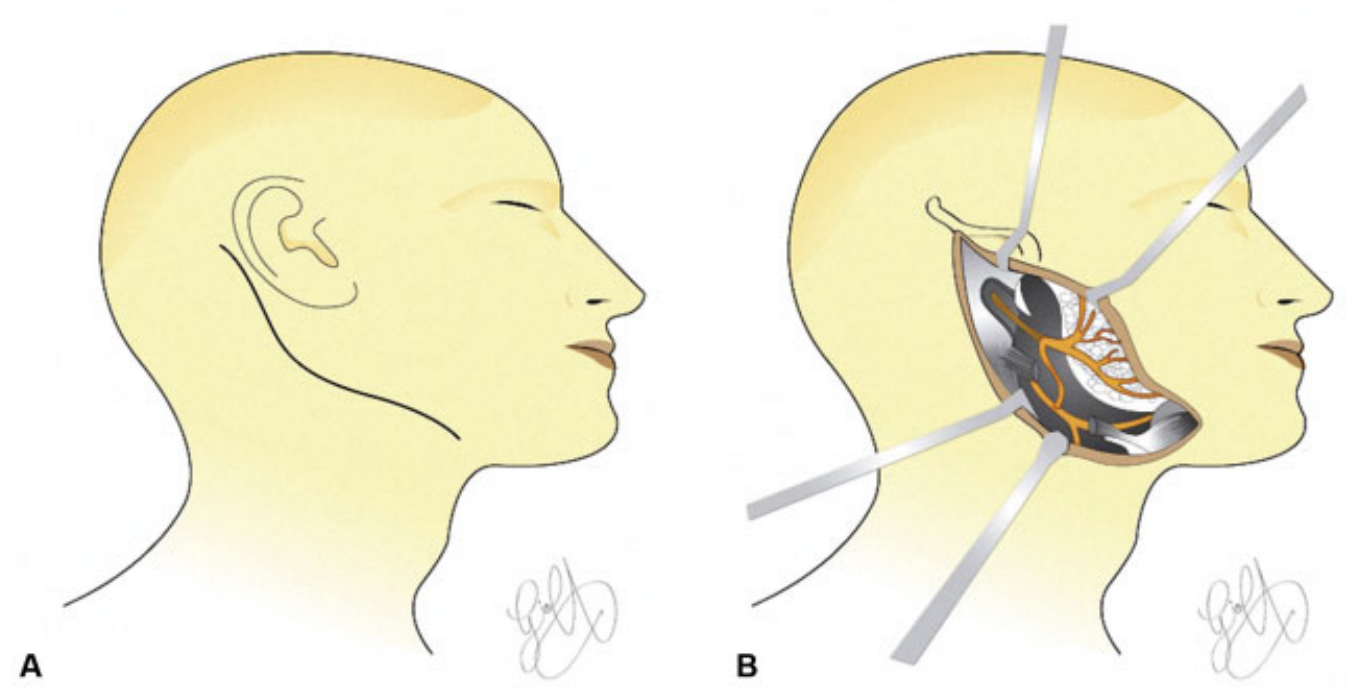

Fig. 1 Schematic demonstration of the side-to-end reconstruction technique. (A) Skin incision; (B) subcutaneous and muscular dissection displaying a branch of the hypoglossal nerve reinervating the facial nerve. 


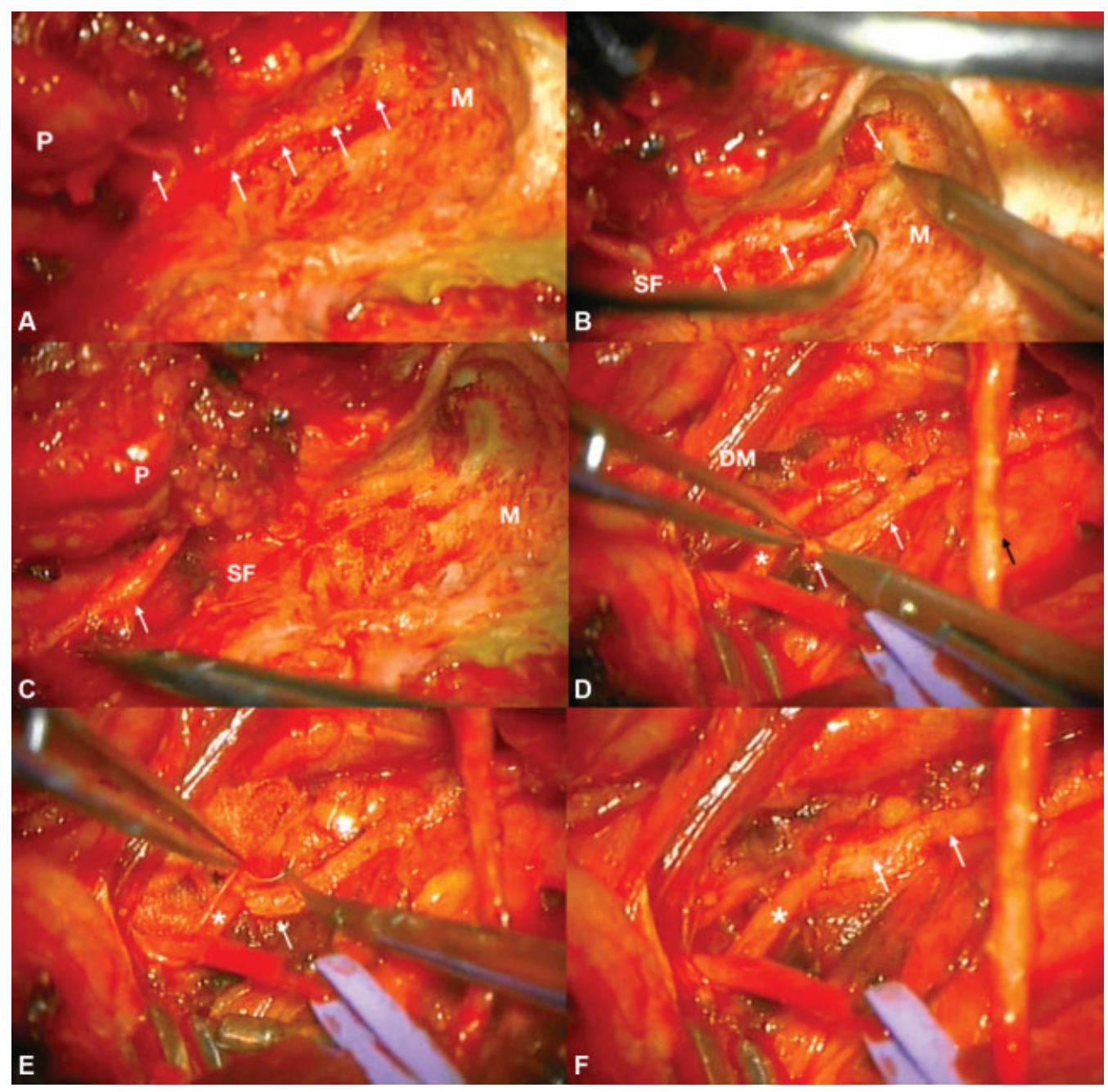

Fig. 2 Anatomical details of the side-to-end reconstruction technique. (A) Partial mastoidectomy of the anterior part of the mastoid process. (B and C) The facial nerve is sectioned near its external genu and then displaced caudally stylomastoid foramen. (D) A longitudinal neurotomy is performed on the hypoglossal nerve, and the distal stump of the facial nerve is prepared; (E) Suture performed with a 10.0 nylon suture of the lateral portion of the hypoglossal nerve with the distal stump of the facial nerve. (F) Final aspect of the anastomosis. White arrow: facial nerve; black arrow: greater auricular nerve; asterisk: hypoglossal nerve; M, mastoid; P, parotid gland; SF, stylomastoid foramen; DM, digastric muscle.

Improvement of the facial paresis was observed in $91.6 \%$ of the patients (11/12). Most patients showed improvement: HB grade III - 58.3\% (7/12); HB grade IV - 16.6\% (2/12); HB grade II - $16.6 \%$ (2/12); and 1 patient (HB grade VI - 8.4\%; 1 / 12) did not recover.

The variables evaluated in the Mann-Whitney U test were postoperative $\mathrm{HB}$ and time of paresis until surgery. Patients with HB II and III had an average time interval between diagnosis and reconstruction surgery of 5.22 months, while patients with HB IV and VI had an average time of paresis of 9.5 months $(p=0.099)$. Although not significant $(p=0.099)$, we observed a tendency for better postoperative HB related to the shorter time of intervention (- Table 2 ).

All patients were evaluated after surgery, and the average time until nerve recovery was of 5.09 months (range: 3 to 12 months). The onset of nerve recovery was also related to the lower mean time of facial paresis $(p=0.011)$. Patients who were operated early, with an average facial paralysis time of 3.5 months, showed signs of nerve recovery in 3 months $(p=0.011)$. Patients with an average of 8.5 months of facial paralysis showed the first signs of recovery in 6 months. (-Table 3).

The only patient who did not have any improvement was the one submitted to a resection surgery due to a brainstem cavernoma. Among the patients who had mild improvement (HB grade IV), one of them had congenital paralysis, and another was submitted to a resection of VS T4B (vestibular schwannoma grade T4b, in Hannover Classification of Vestibular Schwanomas). No patient had lingual atrophy or swallowing dysfunction after surgery.

The side-to-end anastomosis technique favored the recovery of the facial nerve in $91.6 \%$ of the cases, and in $75 \%$ of them the recovery was significant, with variation in minimal facial movement and symmetry (HB II, III).

\section{Discussion}

Facial-nerve injury is a major concern, mainly regarding the surgical removal of vestibular schwannomas. The consequence of the lesion, in addition to its serious functional 
Table 1 Data and results of 12 patients who underwent side-to-end hypoglossal-facial anastomosis

\begin{tabular}{|l|l|l|l|l|l|l|l|l|}
\hline Cases & Gender & Age & Side & HB Pre & HB Post & Paresis Cause & Hypoglossal Paresis & Paresis time \\
\hline 1 & M & 63 & Right & VI & II & VS & N & $4 \mathrm{~d}$ \\
\hline 2 & M & 37 & Right & VI & IV & VS & N & $15 \mathrm{~m}$ \\
\hline 3 & M & 55 & Left & VI & VI & BCA & N & $14 \mathrm{~m}$ \\
\hline 4 & F & 65 & Left & VI & III & VS & N & $18 \mathrm{~m}$ \\
\hline 5 & F & 59 & Left & VI & III & VS & N & $4 \mathrm{~m}$ \\
\hline 6 & M & 7 & Right & VI & IV & CONG & N & $7 \mathrm{y}$ \\
\hline 7 & M & 49 & Right & VI & III & TR & N & $3 \mathrm{~m}$ \\
\hline 8 & M & 61 & Left & VI & III & MEN & N & $2 \mathrm{~m}$ \\
\hline 9 & F & 58 & Right & VI & II & PARAG & N & $6 \mathrm{~m}$ \\
\hline 10 & F & 39 & Left & VI & III & VS & N & $11 \mathrm{~m}$ \\
\hline 11 & M & 42 & Right & VI & III & VS & N & $10 \mathrm{~m}$ \\
\hline 12 & M & 55 & Left & VI & III & VS & N & $7 \mathrm{~m}$ \\
\hline
\end{tabular}

Abbreviations: BCA, brainstem cavernoma; CONG, congenital; d, days; F, female; HB, House-Brackmann facial grading system; m, months; M, male; MEN, meningioma; PARAG, paraganglioma; TR, trauma; VS, vestibular schwannoma; y, years.

Table 2 Facial nerve recovery by average paresis time - 11 patients*

\begin{tabular}{|l|l|l|}
\hline HB Post & N & Average paresis time \\
\hline II and III & 9 & 5.22 months \\
\hline IV and VI & 2 & 9.50 months \\
\hline Total & 11 & $P=0.099$ \\
\hline
\end{tabular}

Abbreviation: HB, House-Brackmann facial grading system.

Note: * Table showing two groups of patients with facial paresis after skull-base-tumor surgery with worse (IV and VI) and better (II and III) outcomes regarding facial-nerve reconstruction. The mean time of paresis until the reconstruction surgery was related to the postoperative result ( $p=0.099$ ). The patient (number 6 ) with congenital facial paresis (with a paresis time of 7 years) was excluded from this sample.

Table 3 Postoperative facial nerve improvement by time of paresis - 10 patients*

\begin{tabular}{|l|l|l|}
\hline Facial nerve outcomes & $\mathbf{N}$ & $\begin{array}{l}\text { Average time from } \\
\text { facial nerve injury } \\
\text { to surgery }\end{array}$ \\
\hline $\begin{array}{l}\text { Onset of improvement } \\
\text { in } 3 \text { months }\end{array}$ & 6 & 3.5 months \\
\hline $\begin{array}{l}\text { Onset of improvement } \\
\text { in } 6 \text { months }\end{array}$ & 4 & 8.5 months \\
\hline Total & 10 & $p=0.011$ \\
\hline
\end{tabular}

Note: ${ }^{*}$ The mean time from the paresis to the reconstruction surgery was related to the onset of nerve recovery $(p=0.011)$. The patient (number 6) with congenital facial paresis (with a paresis time of seven years) was excluded. Patient number 3 was not included in this evaluation, because he did not improve.

deficits, can cause psychological trauma due to facial asymmetry that has been less accepted nowadays. ${ }^{1-3}$ Regarding the different etiologies, the neurosurgeon is more likely to deal with traumatic ${ }^{17}$ and neoplasic lesions. ${ }^{17,18}$ Facial pa- ralysis is one of the main complications in cases of vestibularschwannoma surgery. Even with microsurgical techniques and advances in facial-nerve intraoperative monitoring, facial paralysis remains a feared result, with an incidence of $3 \%$ to $19 \%$ in the main modern series. ${ }^{19-21}$

A wide variety of reconstructive techniques have been described for reconstruction, using muscle transfers, freemuscle grafts, shortening or plication of weakened muscles, dermal transplants, fascial transplants, and redundant-skin removal. ${ }^{22}$ When the the proximal stump of the facial nerve is not available, a neural anastomosis can be performed. The most used donor nerve is the hypoglossus, which is connected to the facial nerve at the level of the stylomastoid foramen.

Facial-nerve reinnervation surgery with HFA is indicated when direct nerve repair is not possible and the facial muscles are viable. The three main indications are loss of the proximal part of the facial nerve at the brainstem in the $\mathrm{CPA}$, destruction of the facial motor nucleus (as in pontine hemorrhages due to cavernomas) and internal axonotmesis. Additionally, as may be presumed, it is also indicated in cases in which, during a CPA operation, the nerve appears to be anatomically preserved, but functional recovery does not occur after 12 months. ${ }^{8}$

The facial and hypoglossal nerves have a cortical topographic proximity in the motor cortex. Both nerves receive afferent input from the trigeminal reflex, and act synergistically in the coordination of some mimic and prandial functions; furthermore, both contain myelinated motor fibers with similar fascicular anatomy. ${ }^{23,24}$

Reinnervation occurs in 4 to 12 months. Approximately $70 \%$ of the patients obtain good results, with the function of the facial nerve classified as "good", or as HB grade III. 18,24 Although some authors initially reported that the onset of facial-nerve remission can occur up to 2 years after tumor resection, the reconstruction operation did not show a 
difference between the early and late treatments. ${ }^{7}$ Therefore, the performance of nerve reconstruction procedures is recommended within six months to one year after the paralysis. After this first year, the results are uncertain and less satisfactory. ${ }^{8,18}$ According to a recent independent metaanalysis of types of techniques, cases within 1 year after facial paralysis had better recovery. ${ }^{5}$ In the present series, we observed that the earlier facial reconstruction was performed, the earlier was the onset of improvement. In the present study, we observed a statistically significant association ( $p=0.011$ ) between the time from facial-nerve injury to reinnervation surgery lower than 4 months, and an onset of improvement within 6 months. This could mean that early surgery would improve the outcome. We examined 12 cases and found a statistically significant result, but we know that a larger sample is needed to corroborate the results of the present study.

Several degenerative phenomena occur during facialnerve injury, such as muscular atrophy, nerve fibrosis, degeneration of the pontine nucleus, and degeneration and loss of information plasticity in the facial area of the motor cortex. Therefore, the reconstruction procedure must be performed before the degenerative mechanisms can evolve, making recovery of facial-nerve function more difficult. ${ }^{8}$

Some studies ${ }^{7}$ have demonstrated a relationship between the improvement in nerve function and the interval until the reconstruction surgery. Patients with delayed surgery did not have a functional improvement as good as that of the patients submitted to surgery before 6 months of the diagnosis. ${ }^{7}$

In the present study, we observed a trend towards a better postoperative HB related to the shorter paresis time ( - Table 2 ). Although without statistical significance $(p=0.099$ ), due to the small sample size, we observed a favorable postoperative evolution in most cases, especially in those patients operated with shorter time of paresis after the diagnosis.

The recovery time of the nerve was also related to a longer interval between the injury and the nerve reconstruction surgery..$^{10}$ In these cases, complete recovery, according to Rebol et $\mathrm{al}^{16}$ and Catli et al, ${ }^{5}$ can be observed after 2 years of the nerve reconstruction surgery. ${ }^{14,25}$ Radiotherapy was also associated to delayed nerve recovery, including a recommendation for these cases of more aggressive resection with early hypoglossal-facial anastomosis, rather than a more conservative resection with partial tumor excision and facial paralysis. $^{10}$

Regarding the causes of the paresis, our results show worst outcomes in one patient after a resection of a cavernous angioma in the brainstem, one case of congenital facial paralysis, and another case of vestibular schwannoma. Studies ${ }^{10}$ show that patients with facial paralysis after resection of a vestibular schwannoma obtained better results than those with meningiomas or other tumors, regardless of the anastomosis technique. ${ }^{10}$ These results were also indicated by other authors ${ }^{5,26}$; they state that even with a short interval between the neural damage and the reconstruction surgery, histopathological findings of greater nerve fibrosis were found. ${ }^{26} \mathrm{~A}$ meta-analysis of 293 patients operated using the end-to-end HFA technique showed that cases with facial paralysis due to traumatic events or facial neuroma had a worse outcome than those with vestibular schwannomas. ${ }^{5}$

The classic end-to-end HFA technique is an effective procedure with excellent facial tonicity in the postoperative control. ${ }^{11}$ However, complete transection of the hypoglossal nerve causes ipsilateral hypoglossal atrophy, with speech and swallowing changes. In addition, the axonal load between the hypoglossal nerve and the facial nerve leads to dyskinesia and spasms. ${ }^{7,9,10}$

A comparison between the classic end-to-end and the side-to-end techniques presented equivalent results in terms of facial-nerve recovery. ${ }^{9,10}$ However, the side-to-end technique minimized tongue atrophy and speech disorders. $^{13,14,26}$ Furthermore, the classic technique is more restricted to patients who already have deficits related to the lower cranial nerves. Hemihypoglossal-facial and masseteric-facial anastomosis are also options to improve facialnerve function with lesser complications. ${ }^{27-31}$ Both techniques present decreased morbidity and average outcomes compared with classic HFA. ${ }^{27-31}$ In many studies in the literature, ${ }^{27-31}$ there is wide evidence to support their application. Although the masseteric-facial anastomosis technique seems to be technically easier, the outcomes tend to be equal or worse than those of the HFA. ${ }^{27-32}$

Regarding the complications of side-to-end HFA, few articles with a low number of patients have been published. In a study conducted by Samii et al, ${ }^{10} 1$ out of 17 patients developed lingual hypotrophy. Two other studies describe a patient with tongue-movement weakness ${ }^{32}$ and another with motility alteration. ${ }^{14}$ In the present study ,we used the side-to-end anastomosis technique, and no complications or major drawbacks, such as tongue atrophy or other swallowing disorders, related to the hypoglossal-nerve section were found.

\section{Conclusion}

Postoperative peripheral facial palsy in skull-base surgery is a condition that can be treated with facial nerve reconstruction techniques such as the HFA. The side-to-end anastomosis technique has significantly favored the recovery of facialnerve function in most cases, with slight changes in symmetry and facial movements. The cases with greater paralysis time were those that had the worst results. In addition, no operated patients had alterations in tongue motility or atrophy, swallowing disorders, or even other complaints related to the hypoglossal-nerve damage.

Conflict of Interests

The authors have no conflict of interests to declare.

\section{References}

1 Asaoka K, Sawamura Y, Nagashima M, Fukushima T. Surgical anatomy for direct hypoglossal-facial nerve side-to-end "anastomosis". J Neurosurg 1999;91(02):268-275

2 Atlas MD, Lowinger DS. A new technique for hypoglossal-facial nerve repair. Laryngoscope 1997;107(07):984-991 
3 Campero A, Socolovsky M. Facial reanimation by means of the hypoglossal nerve: anatomic comparison of different techniques. Neurosurgery 2007;61(03):41-49, discussion 49-50

4 Cardoso AC, Fernandes YB, Ramina R, Borges G. Acoustic neuroma (vestibular schwannoma): surgical results on 240 patients operated on dorsal decubitus position. Arq Neuropsiquiatr 2007;65 (3A):605-609

5 Catli T, Bayazit YA, Gokdogan O, Goksu N. Facial reanimation with end-to-end hypoglossofacial anastomosis: 20 years' experience. J Laryngol Otol 2010;124(01):23-25

6 Cross T, Sheard CE, Garrud P, Nikolopoulos TP, O'Donoghue GM. Impact of facial paralysis on patients with acoustic neuroma. Laryngoscope 2000;110(09):1539-1542

7 Cusimano MD, Sekhar L. Partial hypoglossal to facial nerve anastomosis for reinnervation of the paralyzed face in patients with lower cranial nerve palsies: technical note. Neurosurgery 1994;35(03):532-533, discussion 533-534

8 Darrouzet V, Guerin J, Bébéar JP. New technique of side-to-end hypoglossal-facial nerve attachment with translocation of the infratemporal facial nerve. J Neurosurg 1999;90(01):27-34

9 Dziedzic TA, Kunert P, Marchel A. Hemihypoglossal-Facial Nerve Anastomosis for Facial Nerve Reanimation: Case Series and Technical Note. World Neurosurg 2018;118:e460-e467

10 Yvens FB, Ramina R, Cyrino HS, Proa F Jr, Silva M. Facial reconstruction by hypoglossal-facial neurorrhaphy. Arq Bras Neurocir 2014;33:17-21

11 Koerbel A, Gharabaghi A, Safavi-Abbasi S, Tatagiba M, Samii M. Evolution of vestibular schwannoma surgery: the long journey to current success. Neurosurg Focus 2005;18(04):e10

12 May M, Sobol SM, Mester SJ. Hypoglossal-facial nerve interpositional-jump graft for facial reanimation without tongue atrophy. Otolaryngol Head Neck Surg 1991;104(06):818-825

13 Moubayed SP, Labbé D, Rahal A. Lengthening temporalis myoplasty for facial paralysis reanimation: an objective analysis of each surgical step. JAMA Facial Plast Surg 2015;17(03):179-182

14 Odebode TO, Ologe FE. Facial nerve palsy after head injury: Case incidence, causes, clinical profile and outcome. J Trauma 2006;61 (02):388-391

15 Pitty LF, Tator $\mathrm{CH}$. Hypoglossal-facial nerve anastomosis for facial nerve palsy following surgery for cerebellopontine angle tumors. J Neurosurg 1992;77(05):724-731

16 Rebol J, Milojković V, Didanovic V. Side-to-end hypoglossal-facial anastomosis via transposition of the intratemporal facial nerve. Acta Neurochir (Wien) 2006;148(06):653-657, discussion 657

17 Rosenwasser RH, Liebman E, Jiménez DF, Buchheit WA, Andrews DW. Facial reanimation after facial nerve injury. Neurosurgery 1991;29(04):568-574

18 Samii M, Alimohamadi M, Khouzani RK, Rashid MR, Gerganov V. Comparison of direct side to end and end to end hypoglossalfacial anastomosis for facial nerve repair. World Neurosurg 2015; 84(02):368-375
19 Samii M, Matthies C. Indication, technique and results of facial nerve reconstruction. Acta Neurochir (Wien) 1994;130(1-4): 125-139

20 Samii M, Matthies C. Management of 1000 vestibular schwannomas (acoustic neuromas): surgical management and results with an emphasis on complications and how to avoid them. Neurosurgery 1997;40(01):11-21, discussion 21-23

21 Samii M, Matthies C. Management of 1000 vestibular schwannomas (acoustic neuromas): the facial nerve-preservation and restitution of function. Neurosurgery 1997;40(04):684-694, discussion 694-695

22 Sampath P, Holliday MJ, Brem H, Niparko JK, Long DM. Facial nerve injury in acoustic neuroma (vestibular schwannoma) surgery: etiology and prevention. J Neurosurg 1997;87(01):60-66

23 Sawamura Y, Abe H. Hypoglossal-facial nerve side-to-end anastomosis for preservation of hypoglossal function: results of delayed treatment with a new technique. J Neurosurg 1997;86 (02):203-206

24 Slattery WH III, Cassis AM, Wilkinson EP, Santos F, Berliner K. Sideto-end hypoglossal to facial anastomosis with transposition of the intratemporal facial nerve. Otol Neurotol 2014;35(03):509-513

25 Yetiser S, Karapinar U. Hypoglossal-facial nerve anastomosis: a meta-analytic study. Ann Otol Rhinol Laryngol 2007;116(07): 542-549

26 Ylikoski J, Hitselberger WE, House WF, Sanna M. Degenerative changes in the distal stump of the severed human facial nerve. Acta Otolaryngol 1981;92(3-4):239-248

27 Jandali D, Revenaugh PC. Facial reanimation: an update on nerve transfers in facial paralysis. Curr Opin Otolaryngol Head Neck Surg 2019;27(04):231-236

28 Venail F, Sabatier P, Mondain M, Segniarbieux F, Leipp C, Uziel A. Outcomes and complications of direct end-to-side facial-hypoglossal nerve anastomosis according to the modified May technique. J Neurosurg 2009;110(04):786-791

29 Socolovsky M, Martins RS, di Masi G, Bonilla G, Siqueira M. Treatment of complete facial palsy in adults: comparative study between direct hemihypoglossal-facial neurorrhaphy, hemihipoglossal-facial neurorrhaphy with grafts, and masseter to facial nerve transfer. Acta Neurochir (Wien) 2016;158(05):945-957, discussion 957

30 Martins RS, Socolovsky M, Siqueira MG, Campero A. Hemihypoglossal-facial neurorrhaphy after mastoid dissection of the facial nerve: results in 24 patients and comparison with the classic technique. Neurosurgery 2008;63(02):310-316, discussion 317

31 Kim MJ, Kim HB, Jeong WS, Choi JW, Kim YK, Oh TS. Comparative Study of 2 Different Innervation Techniques in Facial Reanimation: Cross-face Nerve Graft-Innervated Versus Double-Innervated Free Gracilis Muscle Transfer. Ann Plast Surg 2019;84(02): 188-195

32 Murphey AW, Clinkscales WB, Oyer SL. Masseteric Nerve Transfer for Facial Nerve Paralysis: A Systematic Review and Meta-analysis. JAMA Facial Plast Surg 2018;20(02):104-110 